\title{
Server Design Using Raspberry pi for E-Waiter Application in CV. Dcust System Banda Aceh
}

\author{
Husaini $^{1}$, Junaidi Salat ${ }^{2}$, Danil Mahfud ${ }^{3}$ \\ 1,2,2 Univesitas Jabal Ghafur, Indonesia \\ Husaini20unigha@gmail.com,junaidisalat@unigha.ac.id,danilmahfud76@gmail.com
}

\begin{abstract}
Raspberry pi minicomputer is a practical tool in terms of dimensions and has complex functions for various functional needs that will be used by humans as a microcontroller, server to digital images. Technological developments in the field of Internet of Things (IoT) and servers have brought enormous changes for many people. one of them is in the field of cafe service, with the e-waiter application it can provide many benefits for cashier services and cafe management, therefore the authors build a web server for $e$ waiter applications into IoT devices in the form of a Raspberry Pi.The purpose of this research is to build a useful application to facilitate cafe owners in running their business and controlling sales management.
\end{abstract}

\section{Keywords}

minicomputer, raspberry pi;

E-waiter, loT

\section{Introduction}

In today's digital era, many devices are made to help facilitate human work. This is due to the increasing need for things that are practical and fast. Likewise in the case of maximum cafe service and management, the cafe is a promising business in the era of information technology that is currently developing.

Banda Aceh is a city that has a lot of interesting cafes that are loved by young people, the problem is that not many cafe businesses are supported by an optimal service program, so cafe owners cannot always monitor all their business activities such as transactions and sales in their cafes. Therefore, it is necessary to have an application that supports good cafe control management.

Technological developments in the field of Internet of Things (IoT) and servers have brought enormous changes for many people. one of them is in the field of cafe service, with the e-waiter application, one of the superior products of CV. DCUST SYSTEM brings many benefits to service, cashiers and cafe management in Banda Aceh, however, in terms of implementation, many cafes want devices that are paired offline or standby on their computers on the grounds that even though the internet is dead they can still be accessed and carry out activities as usual, then Therefore, to fulfill the client's request, the writer built a web server for the e-waiter application into an IoT device in the form of a Raspberry Pi.

According to Pressman quoted by Buchari et al in the journal E-Journal of Informatics Engineering Vol. 6 No. 1 (2015), design is a series of procedures to translate the results of analysis from a system into a programming language to describe in detail how the system components are implemented. According to Pressman quoted by Taufan in the journal E-Journal of Informatics Engineering Vol. 11 No. 1 (2017), "building or development is the activity of creating a new system or replacing or repairing an existing system as a whole". 
According to Maulani et al in the Journal of ICIT Vol. 4 No. 2 (2018: 157), "Design is creating and creating an application or system that does not yet exist in an agency or object". Based on the above understanding, the researcher concludes that design is a description of the system for creating a new system or updating the previous system.

\section{Review of Literatures}

\subsection{Definition of the Internet of Things (IoT)}

The "thing" in the IoT context can be any device with any internal sender that has the ability to collect and transfer data over the network without manual intervention. The technology embedded in objects helps IoT devices to interact with internal circumstances and the external environment, which in turn helps in the decision making process. In short, IoT is a concept that connects all devices to the internet and allows IoT devices to communicate with each other via the internet.

The IoT is a giant network of connected devices that collect and share data about how a device is used and the environment in which it is operated. By doing so, each device will learn from the experiences gained from other devices, just like humans. IoT tries to expand interpendency in humans, for example interaction, contribution, and collaboration on something.

IoT (Internet of Thing) can be defined as the ability of various devices that can connect and exchange data through the internet network. IoT is a technology that allows for control, communication, collaboration with various hardware, data via the internet network. So it can be said that the Internet of Things (IoT) is when we connect something (things) that are not operated by humans to the internet (Hardyanto, 2017).

But IoT is not only related to remote device control, but also how to share data, virtualize real things into the form of the internet, and so on. The internet becomes a link between machines automatically. In addition, there are also users who act as regulators and supervisors of the operation of these tools directly. The benefit of using IoT technology is that the work done by humans becomes faster, easier and more efficient.

\subsection{Server}

A server is a computer that controls data traffic that occurs on a network, applications stored on this computer and other connected computer terminals can access it. The server is the parent of all computers connected to a network that functions as a network system regulator, for example, to restrict access and control data.

A server is a computer system that provides certain types of services in a computer network. The server is supported by a scalable processor and large RAM, also equipped with a special operating system, which is known as a network operating system. The server also runs administrative software that controls access to the network and the resources contained on it, such as files or printers, and provides access to network member workstations. (Rohmanah, 2014).

\subsection{Rasspberry}

The Raspberry Pi is a credit card sized SBC (Single Board Computer) developed by the Raspberry Pi Foundation in the UK (UK) with the intention of sparking the teaching of basic computer science in schools. Raspberry Pi is an embedded system device in a single board computer type. The Raspberry Pi has a system on the Broadcom bcm 2835 chip with an ARM1176JZF-S $700 \mathrm{MHz}$ processor. Raspberry Pie can be installed with an operating system that supports ARM technology such as RaspbianOS, Arch Linux (Sjogelid, 2013). 
Raspberry Pi is equipped with all the functions like a complete computer, using the ARM SoC (System on a Chip) which is packaged and integrated on a PCB (circuit board) with dimensions of $5.5 \mathrm{~cm} \times 8.5 \mathrm{~cm}$ and a height of $2 \mathrm{~cm}$ as in. (GudangLinux, 2013). Raspberry Pi has two models, namely model A and model B. In general, Raspberry Pi Model B, 512MB RAM. The difference between model A and B lies in the memory used, Model A uses 256 MB memory and model B 512 MB. In addition, model B is also equipped with an ethernet port (network card) which is not found in model A. The Raspberry Pi design is based around the Broadcom BCM2835 SoC (System-on-a-chip) which has embedded an ARM1176JZF-S processor with $700 \mathrm{MHz}$, VideoCore IV GPU, and 256 Megabytes of RAM (model B).

Data storage is designed not to use a hard disk or solid-state drive, but instead relies on an SD card (SD memory card) for booting and long-term storage. The Raspberry Pi is a very inexpensive minicomputer, it costs only \$ 25 for Model A and \$ 35 for Model B per unit. (Almulyadi, 2015)

Table 1. Specifications of the Rasspberry Pi B +

\begin{tabular}{|l|l|}
\hline \multicolumn{1}{|c|}{ Specification } & \multicolumn{1}{c|}{ Needs } \\
\hline Developer & Rasspberry Pi Foundation \\
\hline Type & Single-board computer \\
\hline Release Date & February 2012 \\
\hline Price & US \$ 25 (Model A) \\
& US \$ 35 (Model B, B +) \\
\hline \multirow{3}{*}{ Operating system } & Linux (Raspbian, Debian GNU / Linux, \\
& OpenELEC, Fedora, Arch Linux ARM, \\
& Gentoo) RISC OS, FreeBSD, NetBSD, \\
& Plan 9, Inferno, Openwrt \\
\hline Power & 2.5 W (model A) \\
& 3.5 W (Model B) \\
\hline CPU & 3.0 W (Model B +) \\
\hline Capacity & ARM 1176JZF-S (ARMv6k) 700 MHz \\
\hline & SD Card slot \\
& \\
\hline Memory & 256 MB (Model A) \\
\hline Graphic & 256 MB (Model B rev 1) \\
\hline Website & 512 MB (Brev2, B + models) \\
\hline & Broadcom VideoCore IV \\
\hline & www.rasberrypi.org \\
\hline
\end{tabular}

\subsection{Linux- Operating System}

Linux is an open source operating system software that is free to distribute under the GNU license. So users are allowed to install on a computer or copy and distribute it without having to pay. Linux is a derivative of Unix and can run on a wide variety of computer hardware from Intelx86 to RISC. With the GNU license (Gnu Not Unix) users can get the program, complete with source code (source code). Not only that, users are given the right to copy as many copies as possible or even change the source code. And it's all legal under license. Although free, the GNU license allows parties who wish to charge a fee for both copying and shipping the program. 
In Linux itself, many distributions are better known as distros. These distributions make Linux have many variants. The definition of the distribution itself is an operating system that is pre-loaded with applications, for example Ubuntu, Redhat, Fedora, and so on, respectively distributions have their own advantages (Kukuh Harsabat - 2015).

Linux has long been known for its use in servers, and is supported by leading computer companies such as Intel, Dell, Hewlett-Packard, IBM, Novell, Oracle Corporation, Red Hat, and Sun Microsystems. Linux is used as an operating system on a wide variety of computer hardware, including desktop computers, supercomputers, and embedded systems such as electronic book readers, video game systems (PlayStation 2, PlayStation 3 and XBox), mobile phones and routers.

Information technology observers think Linux's success is due to Linux independent of vendor (vendor independence), low operating costs, and high compatibility compared to non-free UNIX versions, as well as high security and stability factors compared to other operating systems such as Microsoft Windows.

These characteristics are also evidence of the advantages of the open source software development model (opensource software). The Linux operating system, known as a Linux distribution (Linux distribution) or Linux distribution, generally includes supporting software such as web servers, programming languages, databases, desktop environments such as GNOME, KDE and Xfce also have office suite packages such as OpenOffice.org, KOffice, Abiword, Gnumeric and LibreOffice (Amulyadi, 2015).

\subsection{History of Linux}

Linux was originally created by a Finnish student who the name Linus Torvalds. Linux is a hobby project inspired by Minix, a small UNIX system developed by Andrew Tanenbaum. Linux version 0.01 was done around August 1991. Then on October 5, 1991, Linus announced the official version of Linux, which is version 0.02 which can only run the bash shell (GNU Bourne Again Shell) and gcc (GNU C Compiler).

Today Linux is a very complete UNIX system, it can be used for networking, software development and even for everyday work. Linux is now a much cheaper alternative to operating systems when compared to commercial operating systems (eg Windows 9.x / NT / 2000 / ME).

Linux has had a very fast development. This is possible because Linux is developed by various groups of people. This diversity includes levels of knowledge, experience and geography. In order for this group to communicate quickly and efficiently, the internet is the right choice (Almulyadi, 2015).

\subsection{Linux Development}

The main difference between Linux and other popular operating systems lies in the Linux kernel and its free and open components. Linux is not the only operating system in the category. Some free and open source software licenses are based on copyleft principles, a concept that adheres to the principle: works that are produced from copyleft parts must also be copylefted. The most common free software license, the GNU GPL, is a form of copyleft, and is used by the Linux kernel and components of the GNU project. Linux is controlled by its developers and user community. Several vendors develop and finance their own distribution on a voluntary basis. Debian is a great example. Others have community versions of their commercial versions like Red Hat did with Fedora.

In many cities and regions, local associations known as the Linux Users Group (LUG) promote Linux by providing free meetings, demonstrations, training, technical support and installation of the Linux operating system. There are also many Internet 
communities that provide support to Linux developers and users. Many distribution and open source software projects have IRC chat rooms or newsgroups. Online forums are another form of getting support, eg LinuxQuestions.org and Gentoo forums. Linux distributions have mailing lists divided into topics such as usage or development.

\section{Research Methods}

The methodology used in making Server Design in the e-Waiter application using the Raspberry $\mathrm{Pi}$ and compiling this final report is:

1. Study of literature

Read and understand the material related to the Web Server.

2. Literature review

Library research is carried out by reading books, and besides studying the reference web around the same thing to help in presenting the information displayed on internet media related to the problems that will be discussed in writing this thesis proposal.

3. Field Research

By getting direct directions from friends who have learned about Rasspberrry Pi.

a. System Analysis Analyze system requirements and identify information needs based on observations and interviews and literature studies that have been carried out. System analysis tools used in this system are Use Case Diagrams and Class Diagrams.

b. Design and implement a server that will be developed to match what is expected.

\section{Results and Discussion}

\subsection{Raspbian - Rasspberry Pi Os}

Raspbian is an operating system based on Debian which is the Linux platform. The operating system that is officially recommended for use on the Raspberry Pi was created with the aim of supporting the hardware work of the Raspberry Pi, and was launched in July 2012 (Richardson \& Wallace, 2012).

Based on the official website of Raspbian (http://www.raspbian.org), Raspbian is the result of an unofficial port from Debian wheezy armhf (ARM Hard Float). Porting is the process of adapting a program to run in different environments, in this case, with different hardware platforms. ARM Hard Float is an ARM architecture coupled with hardware for floating point operations called VFP (Vector Floating Point).

The addition of this VFP was made to take advantage of the floating point hardware contained in the Raspberry Pi processor, so that processes that require calculations using floating point can be done faster, and can process advanced instructions contained in the ARMv6 architecture. Even so, Raspbian can also be used for non-Raspberry systems that support the above architecture from ARMv6 + VFP (for example ARMv7-A).

\subsection{Web Server}

According to MADCOMS (2016) "Web server is a computer program that has the responsibility or task of receiving HTTP requests from client computers, which are known as web browsers and serving them by providing HTTP responses in the form of data content". There are several types of software to build a local or localhost web server that supports Windows operating systems including Wampserver, Appserv, XAMPP, PHP Triad or Vertigo .. 


\subsection{Understanding PHP (Hypertext Preprocessor)}

According to MADCOMS (2016) "PHP (Hypertext Preprocessor) is a script language that can be embedded or pasted into HTML. PHP is widely used to create dynamic web site programs.

PHP basic components are:

1. Basic PHP syntax There are several syntax rules that must be met when creating PHP program files.

a. PHP opening and closing tag.

b. PHP supports comments such as the ' $\mathrm{C}$ ', 'C ++', and Unix shell-style languages. (Perl style)

2. Constants in PHP We can define a constant using the define () function, which is a feature of PHP functions.

3. Arithmetic in PHP To make it easier to use operands and operators in PHP.

\subsection{SQL / Mysql}

SQL is a multiuser database that uses the Structure QueryLanguange (SQL) language. MySQL in client-server operations involves the MySQL server daemon on the server side and various programs and libraries that run on the client side. SQL is the standard language used to access database servers. By using SQL, the database access process becomes user-friendly compared to using dBase or Clipper which still uses programming commands. According to Sibero (2013: 97) "MySQL or read as" My Sequel "is an RDBMS (Relational Database Management System), which is a system application that performs data processing functions.

According to Hidayatullah and Jauhari (2015: 180) "MySQL is one of the many DBMS applications by web application programmers. Other examples of DBMS are: PostgreSQL (freeware), SQL Server, MS Access from Microsoft, DB2 from IBM, Oracle and Oracle Corp, Dbase, FoxPro, etc. ". Based on the explanation above, it can be concluded that MySQL is a DBMS application that performs data management functions to build a web application.

\subsection{DCUST}

DCUST is a company engaged in the creation and development of information systems, websites, games and android applications, however, there are several things that can be offered to DCUST companies, namely app development, graphic design, creative ideas, marketing, frameworks. DCust company is located in Simpang Surabaya, Banda Aceh, 23127. Chaired by CEO \& founder Rikki Satria, and consists of 8 members in the field of co-CEO, customer development, mobile programmer, web programmer, asst. Customer development, accounting staff, admin staff. Products that have been successfully made are Producte-Waiters, Android Police Bumi Rencong, Android Whistle Ditlantas Polda Aceh, Android Sigemes Satlantas Aceh Besar, Aceh Polda E-Licensing Project, Mobile Storage Rasberry Pi Mobile Store.

\subsection{E-Waiter}

E-Waiter is a Web Base and Android based Electronic Cashier Application, e-Waiter is designed with a user friendly interface so that it is easy to understand and practical in use with the support of many features and is supported by regular system updates via OTA, and can adjust the position of the table and displays notifications about service progress, can display a list of products that are sold and reports as needed. 
With a web-based base and can run online, the e-Waiter can be operated on various devices, and can also run offline on a computer that has the application installed.

\section{Conclusion}

Based on the results of the implementation process, testing and analysis of the system that has been carried out, then in this chapter which is the last chapter of this final project, the author will try to draw conclusions, namely as follows: a). Raspberry Pi can be used for a web server. b). Can run the application offline. C). Raspberry pi can run a web server for E-waiter applications

\section{References}

Almulyadi. 2015. Aceh Polytechnic (Case Study: Mobile Storage Design Using Raspberry $\mathrm{Pi})$.

Amif, Understanding and Advantages of a Web Server. http: // amif. wordpress. com / 2008/07/25 / understanding-and-advantages-of-webserver.

Buchari, Muhamad Z., Steven R. Sentinuwo., And Oktavian A. Lantang. 2015. Design of 3 Dimensional Animation Videos for Motor Vehicle Testing Mechanisms in the Department of Transportation, Culture, Tourism, Communication and Information. E-Journal of Informatics Engineering. Vol. 6 No. (1).

Dawood, Rahmad, 2014. Feasibility Analysis of Raspberry Pi as a Web Server. Essay. Banda Aceh: Faculty of Engineering, Syiah Kuala University.

Giandri Maulani, et al. 2018.DESIGN OF INFORMATION SYSTEMS INVENTORY MAINTENANCE FACILITIES IN. PLN (PERSERO) TANGERANG. ICIT EJournal. Vol. 4 No. (2).

Hidayatullah, Priyanto, and Jauhari Khairul Kawistara. 2017. WEB programming. Bandung. Bandung Informatics.

Jubilee Enterprise. 2014 Tricks to Create Computer and Wi-Fi Networks, Elex Media Komputindo.

MADCOMS MADIUN. 2016 "Programming PHP and MySQL for Beginners" Publisher Andi Yogyakarta.

Sibero, Alexander FK 2013. Web Programming Power Pack. Yogyakarta: MediaKom.

Syarifah Lanaya. 2016. Jabal Ghafur University (Case Study: Design and Build a free phone voip server via wifi using rasspberry pi

Taufan Yusuf Aslah, et al. 2017.Designing a 3D animation of the Watu Pinawetengan Cultural Museum Tourism Object.E-Journal of Informatics Engineering. Vol. 11 No. (1). 